\title{
Addition of Valerian and Lemon Balm Extract to Quetiapine Reduces Agitation in Critically Ill Patients with Delirium: A Pilot Randomized Clinical Trial
}

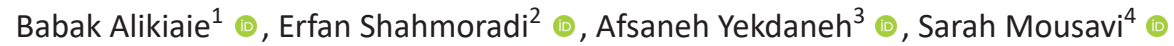

\begin{abstract}
Background: This study was pointed to evaluate the efficacy and safety of valerian and lemon balm additional to the quetiapine in critically ill patients with delirium and agitation.

Methods: We conducted a randomized, double-blind, placebo-controlled study. Fifty-three adult intensive care unit (ICU) patients (according to ICU Confusion Assessment Method scores) who were treated for delirium received quetiapine and Neurogol syrup (a combination of valerian and lemon balm) or placebo $5 \mathrm{~mL}$ every 12 hours for five consecutive days. Improvement in agitation according to the Richmond Sedation and Restlessness Scale was considered the main outcome.

Results: The trial was completed for 53 patients ( 27 in the treatment group and 26 in the placebo group). The baseline characteristics between the groups were similar. In the treatment group, the number of agitated patients was significantly reduced and the difference was statistically significant $(p=0.000)$. Compared with the placebo group, the length of ICU stay in the treatment group was significantly reduced $(p=0.001)$. The Glasgow Coma Scale improved significantly at the end of day $5(p=0.04)$. There was no statistical difference in the improvement of delirium between the study groups $(p=0.14)$. Neurogol syrup was well tolerated.

Conclusion: The addition of Neurogol to quetiapine (a combination of valerian and lemon balm) can reduce agitation and shorten the length of stay in the ICU without adverse effects. Clearly, more research is still needed to investigate the role of herbal medicines in ICUs and their efficacy and safety.

Keywords: Delirium, Lemon balm, Quetiapine, Valerian.

Indian Journal of Critical Care Medicine (2021): 10.5005/jp-journals-10071-23854
\end{abstract}

\section{INTRODUCTION}

Delirium is a common manifestation in the intensive care unit (ICU) with a frequency of $80 \%$. Fluctuation in the level of consciousness and disturbance in ability to attention are the main characteristics of delirium. The pathophysiology of delirium is complex. Severalpathologic conditions interfere consciousness and attention of the patient, which makes the diagnosisdifficult., ${ }^{1,2}$

Unrecognition of delirium leads to increased risk of mortality, longer mechanical ventilation, and long-term cognitive impairment; therefore, recent ICU guidelines recommend early detection, prevention, and treatment of delirium. ${ }^{3}$

Most ICUs typically use interventions, such as eliminating any causative factors, changing the environment (such as reducing ambient noise and alarms), and various strategies to promote sleep to reduce or prevent irritation delirium. ${ }^{3,4}$ However, these interventions are not completely effective in preventing or eliminating delirium, and patients are treated with psychotropic medications on a regular basis. ${ }^{4}$ To date, there is no evidence available that the normal use of antipsychotics is effective in treating delirium. ${ }^{5}$ The latest guidelines for the prevention and treatment of delirium in the ICU do not recommend the routine use of haloperidol, an atypical antipsychotic, dexmedetomidine, or ketamine. " "Unless the treatment of special circumstances, the use of benzodiazepines in the ICU should be avoided." ${ }^{6}$ Dexmedetomidine is a promising agent for managing delirium (hyperactive) and it is a better treatment strategy than benzodiazepine administration. ${ }^{7}$ Some of the new strategies, such as dexmedetomidine, are not
${ }^{1}$ Department of Anesthesiology and Intensive Care, Al-Zahra Hospital, Isfahan University of Medical Sciences, Isfahan, Iran

${ }^{2}$ School of Pharmacy and Pharmaceutical Sciences, Isfahan University of Medical Sciences, Isfahan, Iran

${ }^{3}$ Department of Pharmacognosy, School of Pharmacy and Pharmaceutical Sciences, Isfahan University of Medical Sciences, Isfahan, Iran

${ }^{4}$ Department of Clinical Pharmacy and Pharmacy Practice, School of Pharmacy and Pharmaceutical Sciences, Isfahan University of Medical Sciences, Isfahan, Iran

Corresponding Author: Sarah Mousavi, Department of Clinical Pharmacy and Pharmacy Practice, School of Pharmacy and Pharmaceutical Sciences, Isfahan University of Medical Sciences, Isfahan, Iran, Phone: +983137927072, e-mail: s.mousavi@pharm. mui.ac.ir

How to cite this article: Alikiaie B, Shahmoradi E, Yekdaneh A, Mousavi S. Addition of Valerian and Lemon Balm Extract to Quetiapine Reduces Agitation in Critically III Patients with Delirium: A Pilot Randomized Clinical Trial. Indian J Crit Care Med 2021;25(7):785-790.

Source of support: Nil

Conflict of interest: None

routinely available in ICUs at our centers. Therefore, physicians' strategy is based on the administration of atypical antipsychotics (mostly quetiapine) for treating delirium and using haloperidol and benzodiazepines for acute agitation (hyperactive delirium). 
Benzodiazepines are effective and selective medicines such as sedatives in non-ICU settings, but their administration in ICU increases the risk of delirium. ${ }^{7}$ Use of antipsychotics for delirium with agitation can cause serious adverse events. Use of antipsychotics for delirium with agitation can cause serious adverse events. Thus, the latest studies have evaluated the effects of nonpharmacological treatments, such as reorienting the patient, involvement of families, and avoiding the use of physical restraints, and use of workout, physical, light, and music therapies.Another treatment option is complementary and alternative medicine, where one category of complementary and alternative medicine is therapies based on natural products (including herbal medicine). ${ }^{8-11}$ Considering the prevalence of delirium and agitation and the limitations of standard care for these conditions, we evaluated the role of herbal medicine (combination of Melissa officinalis and Valeriana officinalis) in this setting.

Melissa or lemon balm is an herb in the mint family Lamiaceae and has been prescribed in traditional medicine to treat diseases of the gastrointestinal tract, nervous system, liver, and bile. ${ }^{12}$ Note that lemon balm is generally associated with antistress and antianxiety effects. Previous studies have shown that, compared to healthy people, the calm of healthy people is significantly improved, in addition to improving mood and cognitive abilities. ${ }^{13,14}$ Some studies also support the effect of lemon balm in reducing agitation in patients with dementia. ${ }^{15}$ "The presumed biologically active compounds in lemon balm include monoterpenic aldehydes, flavonoids, and polyphenolic compounds, such as rosmarinic acid and monoterpenic glycosides." Because the herb binds to nicotinic and muscarinic acetylcholine receptors in the central nervous system, it enhances cholinergic transmission. ${ }^{16,17}$ The cognitive regulation effect of M.officinalis may be due to its activity in the cholinergic system. ${ }^{18}$

V.officinalis (valerian) is a native plant in Europe and Asia with sedative and anxiolytic effects. Valerian has been used for treating insomnia and anxiety in traditional medicine. ${ }^{19}$ Valerian has a mechanism of action similar to benzodiazepines. However, it appears to bind to the $\beta$ subunit of the GABA-A receptor, rather than to the $\gamma$ subunit like benzodiazepines. Valeric acid stimulates the serotonin receptor $(5-\mathrm{HT} 5 \mathrm{~A})$ as a partial agonist. ${ }^{20}$ The combination of valerian and lemon balm can be purchased as a standard product on the Iranian pharmaceutical market under the brand name Neurogol. ${ }^{21}$

Quetiapine has been used in our center for the treatment of delirium, and benzodiazepines have been often prescribed as a sedative for managing agitation, which is not only a standard of care but also should be avoided in delirium. Taking into account, the prevalence of delirium and agitation and the restrictions of standard care for these conditions, we conducted this randomized, placebo-controlled trial to evaluate the efficacy and effectiveness of valerian and lemon balm combined withquetiapine in critically ill patients with delirium and agitation.

\section{Methods}

The study was designed as a randomized, double-blind, placebocontrolled study, and the study was conducted from June 2019 to February 2020. The protocol used has been approved by the Ethics Committee of Isfahan Medical University (IUMS). Informed consent was also obtained from all patients. The study population included consecutive patients in the ICU of the tertiary university hospital "AL Zahra Hospital" (Isfahan, Iran).

Critically ill adult patients (age $>18$ years) with delirium who were tolerating enteral nutrition enrolled in the study. Delirium was assessed by the "Confusion Assessment Method for the Intensive Care
Unit (CAM-ICU)" score ${ }^{22}$ and tolerating of enteral nutrition considered as gavage rate of $\geq 20 \mathrm{~mL} /$ hour. for at least 12 hours. Patients with conditions that prevent delirium assessment including admission with neurologic diseases such as intracranial hemorrhage, history of cognitive dysfunction such as dementia and patients with hearing loss or on coma excluded from the study. Also patients treated with antipsychotic treatment 30 days prior to ICU admission, and currently received dexmedetomidine or a neuromuscular blocker or treated with drugs that can affect the concentration of quetiapine (such as phenytoin) or increase the risk of QTc interval prolongation (such as erythromycin or any type la, Ic, or III antiarrhythmic), were not enrolled in the study. Other exclusion criteria were as follows: end-stage liver disease (Childs-Pugh class B or more severe), pregnancy, very poor prognosis, patients receiving continuous infusion of midazolam or any conventional dose of benzodiazepines, previous history of sensitivity to herbs such as valerian and lemon balm, and informed consent could not be obtained from an official representative office.

For allocating the participants, a computer-generated list of random numbers was used. Eligible participants were randomly assigned 1:1 to the treatment group or the placebo group according to a predefined randomization list (block size is 4). The study coordinator (without clinical participation in the trial) performed the randomization and provided the study drugs. Neurogol and placebo were in syrup form and they were prepacked in the bottles and consecutively numbered for each subject according to the randomization schedule. All patients, who fulfilled the inclusion criteria, were randomized. Randomization was requested by the principle investigator for recruitment and responsible physician of ICU.Subsequently, the principal investigator obtained the patient's consent and called the study coordinator to order the shipment. The research coordinator kept the random password in a sealed envelope and opened it after the intervention. Patients, physicians, nurses, and principal investigators are unaware of the task of treatment.

At the time of enrollment, the following baseline demographic data were collected: age, gender, admission diagnosis, use of sedatives, and analgesics in the last 24 hours, level of consciousness [according to the Glasgow Coma Scale (GCS)], location before ICU admission, intubation status, length of stay in ICU and hospital, and mortality rate. Sequential Organ Failure Assessment (SOFA), Acute Physiological Assessment, and Chronic Health Assessment (APACHE) II scores were obtained at ICU admission and study randomization. The Richmond Agitation Sedation Scale (RASS) was used to assess the level of agitation. ${ }^{23}$

A validated Persian version of the standard CAM-ICU tool was used to assess delirium. ${ }^{24,25}$ CAM-ICU is most common in ICU patients and has been validated in multiple languages around the world. ${ }^{22 ~ " T h e ~ t e s t ~ c a n ~ p r o v i d e ~ a ~ h i g h l y ~ s e n s i t i v e, ~ s p e c i f i c, ~ a n d ~}$ reliable interobserver tool to assess the incidence of delirium. CAM-ICU displays four key characteristics, including(1) the process of sudden onset or fluctuation of mental state, (2) lack of attention, (3) confusion, and (4) changes in the level of consciousness, so that in addition to traits 3 and 4, in the presence of traits 1 and 2, the patient is considered delusional positive..$^{\prime 11}$ Therefore, each item is scored according to the patient's response to each question posed during the standardized interview. All intensive care nurses have received adequate education on CAM-ICU scores.

Eligible patients in both groups received quetiapine. Therapy was initiated at $50 \mathrm{mg}$ every 12 hours and it was administered orally or via NG tube. The in-charge physicians titrated upward quetiapine by raise of $50 \mathrm{mg}$ every 12 hours to a maximum dose of $200 \mathrm{mg}$ 
every 12 hours. The treatment group received $5 \mathrm{~mL}$ Neurogol syrup (Goldaru, Isfahan, Iran) every 12 hours, for fiveconsecutive days in addition to quetiapine. Patients in the control group received placebo, in the same dose for fiveconsecutive days. The placebo was prepared by the Goldaru Company containing expedients without effective compounds especially valerian and lemon balm. The investigator delivered the drug or placebo in the same packaging containers. Neurogol syrup contained $625 \mathrm{mg}$ of V.officinalis root and $50 \mathrm{mg}$ M.officinalis leaves in every $5 \mathrm{~mL}$, which equals to $0.2 \mathrm{mg}$ of sesquiterpenoid acid in every $5 \mathrm{~mL} .^{26}$

Depending on the condition of the prescriber and the patient, quetiapine were continue to be administered for more than 5 days. All sedation and analgesia prescription options should be determined by the subject's intensive care physician and not as part of the study.

After enrollment, the patient were be excluded from the study if any of the following occurs: adverse events (such as hypersensitivity reactions) to the study drug, discharge of patients from ICU earlier than 5 days, or any reason according to the decision of the responsible physician.

The primary outcome was improvement in agitation based on the RASS scale. For all patients, the intensive care nurse should record on the ICU flow chart at least every 4 to 6 hours. Before the intervention and on days 1 to 5 of the study, the researchers recorded the RASS scores of the patients enrolled in the study. "RASS is a 10-point system, ranging from -5 to $+4 .{ }^{23}$ Levels from -1 to -5 indicate fivelevels of sedation, starting withwake-up sound and ending withdo not wake."Levels +1 to +4 describe increasing levels of agitation. The lowest degree of restlessness begins with worry and anxiety, and peaks when it is combative and violent. RASS 0 is "alert and calm." If the RASS score is between +2 and +4 , the patient is documented as agitated.

As the secondary outcomes, resolution of delirium according to CAM-ICU score, improvement in consciousness based on GCS and also APACHE II and SOFA scores, ICU stay timeand duration of mechanical ventilation, and hospital mortality were all evaluated.
Delirium assessments were completed by the patient's bedside nurse at baseline and at days 1 and 5 of the interventions. Resolution of delirium was considered as the negative CAM-ICU score.

A person's GCS score ranges from 3 (completely unresponsive) to 15 (responsive). It was documented in the ICU flow sheets every 3 hours for all patients. At baseline and across the interventions, GCS was recorded and improvement in awareness was considered to be an increase in GCS from day 1 to day 5 of the intervention. At baseline, APACHE II and SOFA scores were calculated for each subject on day 1 and day 5 .

In this study, we assumed that delirium and agitation would be resolved in $50 \%$ of subjects treated with quetiapine and placebo and in $80 \%$ of subjects treated with quetiapine and Neurogol. Based on these assumptions, we calculated that 38 subjects in each group would provide $>80 \%$ power to find a significant difference with an alpha value of 0.05 on both sides. Due to the COVID-19 outbreak, we ended the study after 53 patients were enrolled (before the expected endpoint).

All data collected in standard format is imported into the SPSS (statistical software package for social sciences) version. Twentythreesoftware for a more detailed analysis. Frequency and percentage are used for categorical variables, and mean and standard deviation are used for continuous variables. In addition, the chi-square test, the Mann-Whitney $U$ test, and the McNemar test were used to compare categorical and continuous variables between the two groups.To investigate the consistency of treatment effects across those subjects with improved delirium, we performed subgroup analysis. All statistical analyses were conducted at a significant level ( $p$-value $<0.05)$.

\section{Results}

During the study period, $128 \mathrm{ICU}$ patients were examined, of which 71 were excluded. The ratio of the remaining patients ( 27 in the treatment group and 26 in the placebo group) was 1:1. The reasons for treatment discontinuation are reported in Figure 1.

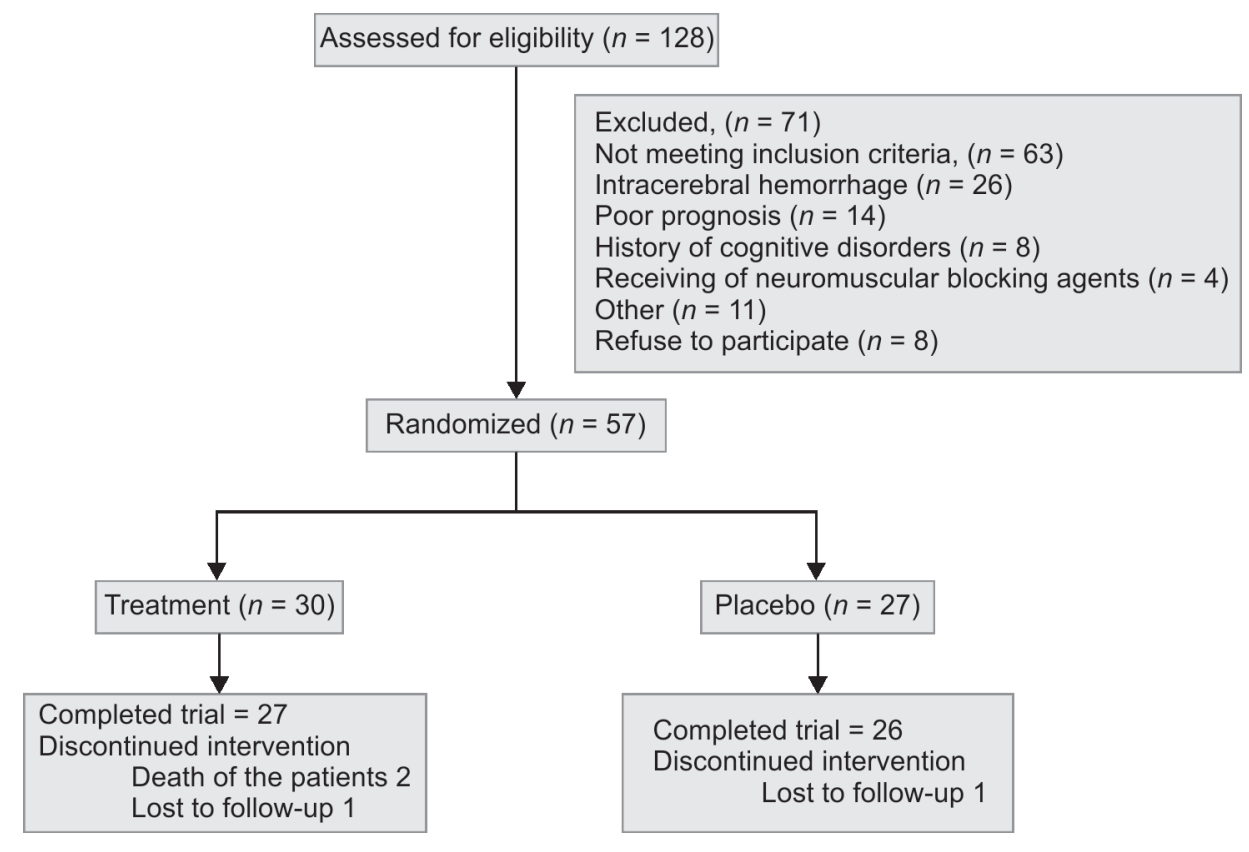

Fig. 1: Progress through the stage of trial 
Table 1: Characteristics of patients

\begin{tabular}{|c|c|c|c|}
\hline & $\begin{array}{l}\text { Treatment } \\
\text { group } \\
(N=27)\end{array}$ & $\begin{array}{l}\text { Placebo } \\
\text { group } \\
(N=26)\end{array}$ & $\begin{array}{l}p \text { value (non- } \\
\text { parametric) }\end{array}$ \\
\hline $\begin{array}{l}\text { Age (years) (mean } \pm S D ; \\
\text { range) }\end{array}$ & $\begin{array}{l}49.7 \pm 20.6 \\
(18-83)\end{array}$ & $\begin{array}{l}56.6 \pm 19.7 \\
(18-97)\end{array}$ & 0.22 \\
\hline Male/female & $16 / 10$ & $16 / 10$ & 1 \\
\hline \multicolumn{4}{|l|}{ Initial diagnosis } \\
\hline Multiple trauma & $9(30 \%)$ & $4(26.7 \%)$ & \\
\hline Cerebrovascular accident & $1(20 \%)$ & $4(33.3 \%)$ & \\
\hline Brain tumor & $1(10 \%)$ & $3(23.3 \%)$ & \\
\hline Sepsis & $0(20 \%)$ & $2(16.7 \%)$ & \\
\hline COPD & $0(6.7 \%)$ & $2(0)$ & 0.01 \\
\hline Pneumonia & $1(6.7 \%)$ & $1(0)$ & \\
\hline Hydrocephalus & $1(6.7 \%)$ & $1(0)$ & \\
\hline Pulmonary thromboem- & 1 & 1 & \\
\hline bolism & 1 & 1 & \\
\hline Aneurysm & 11 & 7 & \\
\hline \multicolumn{4}{|l|}{ Other } \\
\hline Clinical data (mean $\pm S D$ ) & $10.6 \pm 4.7$ & $10.8 \pm 3.4$ & 0.85 \\
\hline APACHE II at admission & $12.7 \pm 4.7$ & $13.7 \pm 4.8$ & 0.61 \\
\hline APACHE II day 1 & $11.5 \pm 4.8$ & $12.9 \pm 4.7$ & 0.38 \\
\hline \multirow[t]{2}{*}{ APACHE II day5 } & $12.7 \pm 1.2$ & $12.6 \pm 0.97$ & 0.71 \\
\hline & $10.6 \pm 1.5$ & $10.6 \pm 1.4$ & 0.92 \\
\hline GCS at admission & $11.8 \pm 1.4$ & $11.0 \pm 1.4$ & 0.04 \\
\hline GCS-1 & $4.4 \pm 1.6$ & $4.1 \pm 1.5$ & 0.52 \\
\hline \multirow[t]{2}{*}{ GCS-5 } & $5.3 \pm 1.6$ & $5.1 \pm 1.8$ & 0.61 \\
\hline & $4.9 \pm 1.9$ & $4.8 \pm 1.8$ & 0.71 \\
\hline SOFA at admission & $28.8 \pm 14.6$ & $48.2 \pm 27.9$ & 0.001 \\
\hline SOFA-day 1 & 22 & 19 & 0.11 \\
\hline \multicolumn{4}{|l|}{ SOFA-day 5} \\
\hline Length of ICU stay & $24 / 3$ & $20 / 6$ & 0.49 \\
\hline \multicolumn{4}{|l|}{$\begin{array}{l}\text { Number of patients on } \\
\text { mechanical ventilation }\end{array}$} \\
\hline Survival, alive/dead & & & \\
\hline
\end{tabular}

There were no statistical differences in baseline characteristics between the two groups (Table 1). Multiple trauma (33.3\%) and cerebrovascular accident (15.3\%) were the most frequent admission diagnoses.

Table 1 summarizes GCS, APACHE II, and SOFA.After 5 days of intervention, there were no significant differences in SOFA and APACHE II scores between the two groups. However, there was a significant improvement in GCS at the end of day 5 ( $p=0.04$ ). There was no significant difference in the number of mechanically ventilated patients between the two groups $(p=0.1)$. However, compared to the placebo group, the length of ICU stay in the treatment group was significantly reduced $(p=0.01)$. The difference in mortality between the two groups was not significant $(p=0.25)$.

Regarding the main outcome (degree of agitation), the number of agitated patients in the treatment group was significantly reduced ( $p=0.000$ ). In within-group analysis, the number of patients in the placebo group was significantly reduced $(p=0.021)$. Regarding the secondary outcomes, there was no statistically significant difference in the resolution of delusions between the study groups ( $p=0.14$ ) (Table 2 ).

Subgroup analysis based on the patients with improved delirium showed that the addition of Neurogol significantly improved agitation in comparison with those patients without improved delirium (Table 3). The results of within-group subanalysis
Table 2: Comparison of groups according to RAAS score and level of agitation

\begin{tabular}{llll}
\hline & $\begin{array}{l}\text { Treatment } \\
\text { group }(N=27)\end{array}$ & $\begin{array}{l}\text { Placebo } \\
\text { group } \\
(N=26)\end{array}$ & $\begin{array}{l}\text { pvalue } \\
\text { (between } \\
\text { groups) }\end{array}$ \\
\hline $\begin{array}{l}\text { Number of patients } \\
\text { with agitation-day 1 }\end{array}$ & 21 & 18 & 0.25 \\
$\begin{array}{l}\text { Number of patients } \\
\text { with agitation-day } 5 \\
p \text { value (within } \\
\text { groups) }\end{array}$ & 4 & 10 & 0.0001 \\
$\begin{array}{l}\text { Outcome after } \\
5 \text { days }{ }^{* *}, N\end{array}$ & $0.0001^{*}$ & $0.021^{*}$ & \\
$\begin{array}{l}{ }^{*} \text { Mc Nemar; } \\
*{ }^{* *} \text { Improvement of delirium according to CAM-ICU score; RASS, Richmond } \\
\text { agitation sedation scale }\end{array}$ & 21 & & \\
& & &
\end{tabular}

also confirmed this achievement $(p=0.000)$. However, the clinical scores (GCS, SOFA, and APACHE II) were not significantly different even in the subgroup analysis $(p>0.05)$ (Table 4).

\section{Discussion}

The achievements of this randomized, double-blind, and placebocontrolled study showed that the addition of Neurogol (combination of valerian and lemon balm) to quetiapine significantly improved agitation after 5 days of intervention. Moreover, the length of ICU stay was significantly decreased in the treatment group. It is noted that quetiapine itself is an effective modality for the treatment of delirium and the addition of Neurogol augmented the effect of quetiapine for controlling delirium without unfavorable side effects like those of benzodiazepines. The subgroup analysis confirmed the effect of Neurogol in patients in whom delirium was improved. Neurogol could be seen as an effective modality in the management of patients with delirium and agitation.

Benzodiazepines administration should be avoided or restricted in the ICU patients according to the guidelines recommendation ${ }^{3}$; therefore, we excluded the patients who received this class of drugs within this study. As a result, we concluded that the improvement of agitation was thesole effect of Neurogol in this study. The exact mechanisms of antianxiety and agitation of valerian and lemon balm are not clear but estimating that the positive effect could be through the other pathways except the GABA of benzodiazepines impacts. Agonistic effect on serotonin pathway and other subtypes of GABA and cholinergic receptors are the recommended mechanisms of action for Neurogol. ${ }^{12}$

Watson et al. ${ }^{27}$ studied 39 subjects of dementia and agitated behaviors with essential oils of lavender and lemon balm. Their achievement showed asignificant reduction of agitated behavior with a dominant role of lemon balm $(p=0.04)$. We also obtained parallel results, in which the positive effect of lemon balm was dominant for reduction of agitation. Similarly, Elliot et al. ${ }^{28}$ confirmed the role of essential oils from lavender and lemon balm in the potential treatment of severe dementia subjects.

Akhondzadeh et al. ${ }^{15}$ indicated the efficacy of M.officinalis extracts in the management of mild to moderate Alzheimer's disease in 42 patients. It is known that the pathophysiology of Alzheimer's disease is different from dementia, but both of them could be considered in the category of cognitive disorders with the benefits of employing natural treatments of herbal medicine. 
Table 3: Subgroups analysis ${ }^{\mathrm{a}}$ according to RAAS score and level of agitation

\begin{tabular}{|c|c|c|c|c|c|}
\hline & $\begin{array}{l}\text { Treatment = yes } \\
\text { Group A }\end{array}$ & $\begin{array}{l}\text { Treatment }=\text { no } \\
\text { Group } A\end{array}$ & $\begin{array}{l}\text { Treatment }=\text { yes } \\
\text { Group B }\end{array}$ & $\begin{array}{l}\text { Treatment }=\text { no } \\
\text { Group B }\end{array}$ & $\begin{array}{l}\text { p value } \\
\text { (between) }\end{array}$ \\
\hline Number of patients without agitation-day 1 & 4 & 2 & 4 & 4 & $0.03^{* * *}$ \\
\hline Number of patients without agitation-day 5 & 20 & 3 & 10 & 6 & $0.86^{* * *}$ \\
\hline$p$ value (within) & $0.0001^{* *}$ & - & $0.25^{* * *}$ & - & \\
\hline Length of ICU Stay & $29.2 \pm 14.7$ & $27.5 \pm 15.3$ & $50.4 \pm 33.8$ & $45.2 \pm 18.2$ & \\
\hline$p$ value (between) & $0.013^{* *}$ & - & $0.06^{* * *}$ & - & \\
\hline
\end{tabular}

${ }^{* *} p$ value in patients who treated;

${ }^{* * *} p$ value in patients who are not treated;

a Subgroup analysis performed according to whom treated means the delirium improved according to CAM-ICU score

Table 4: Subgroup analysis ${ }^{\mathrm{a}}$ according to APACHE and GCS and SOFA score.

\begin{tabular}{|c|c|c|c|c|c|}
\hline & $\begin{array}{l}\text { Treatment = yes } \\
\text { Group A }\end{array}$ & $\begin{array}{l}\text { Treatment }=\text { no } \\
\text { Group A }\end{array}$ & $\begin{array}{l}\text { Treatment }=\text { yes } \\
\text { Group B }\end{array}$ & $\begin{array}{l}\text { Treatment }=\text { no } \\
\text { Group B }\end{array}$ & $\begin{array}{l}p \text { value } \\
\text { (between group) }\end{array}$ \\
\hline APACHE—day 1 & $12.7 \pm 4.5$ & $14 \pm 5.1$ & $13.2 \pm 5$ & $14.4 \pm 4.6$ & $0.29^{* *}$ \\
\hline APACHE—day 5 & $10.6 \pm 3.8$ & $15.7 \pm 5.4$ & $10.4 \pm 2.7$ & $16.3 \pm 4.7$ & $0.81^{* * *}$ \\
\hline$p$ value (within group) & $0.66^{* *}$ & - & $0.83^{* * *}$ & - & \\
\hline SOFA-day 1 & $4.8 \pm 1.4$ & $6.8 \pm 1.2$ & $4.8 \pm 1.7$ & $5.4 \pm 2$ & $0.92^{* *}$ \\
\hline SOFA-day 5 & $4.1 \pm 1.4$ & $6.8 \pm 2.1$ & $4.2 \pm 1.2$ & $5.5 \pm 2.4$ & $0.19^{* * *}$ \\
\hline$p$ value (within group) & $0.72^{* *}$ & - & $0.9^{* * *}$ & - & \\
\hline GCS—day 1 & $10.6 \pm 1.5$ & $12.1 \pm 1.2$ & $10.6 \pm 1.5$ & $11.4 \pm 1.3$ & $0.66^{* *}$ \\
\hline GCS-day 5 & $12.1 \pm 1.2$ & $10.8 \pm 1.6$ & $11.4 \pm 1.3$ & $10.4 \pm 1.4$ & $0.9^{* * *}$ \\
\hline$p$ value (within group) & $0.27^{* *}$ & & $0.42^{* * *}$ & & \\
\hline
\end{tabular}

${ }^{* *} p$ value in patients who treated;

${ }^{* * *} p$ value in patients who are not treated;

a Subgroup analysis performed according to whom treated means the delirium improved according to CAM-ICU score

Traditionally, valerian has been used as an antianxiety agent and further studies confirmed its positive effects. Recently, valerian was compared with diazepam and placebo in a clinical trialof the generalized anxiety subjects by Andreatini et al. ${ }^{29}$ showing that anxiety was significantly improved according to Hamilton score but without significant difference between the groups. The small sample size $(N=36)$ was the principle limitation of this study. ${ }^{29}$ Our results showed that valerian could be an effective agent in the reduction of agitation.

Trompetter et al. ${ }^{30}$ studied treatment of herbal triplet (St. john worth, valerian, and passionflower) for 115 children with nervous agitation, regarding the agitated depression. The response rate was 81.6 to $93.9 \%$ and the treatment was well tolerated.

Acute agitation (hyperactive delirium) is less than prevalent than the hypoactive type, ${ }^{31}$ but it could cause more trouble for the nurses and intensivists. The agitated patients are usually physically restricted and the stat dose of haloperidol and benzodiazepines and other sedatives even analgesics are used to sedate these patients. This approach not only increases the chance of delirium (the hypoactive type) but also mortality, prolonged hospital stay, mechanical ventilation and total health care costs are all increased by deep sedation of patients. ${ }^{32}$ Therefore, most guidelines recommended against the routine use of sedative such as benzodiazepines.

Our herbal intervention with Neurogol was effective in the management of agitation without deep sedation and other side effects of benzodiazepines and haloperidol. As the results show, the length of ICU stay was significantly reduced and the level of consciousness was improved after 5 days of intervention. Even, it seems that delirium was better controlled in the treatment group.
Hence, Neurogol is valuable for the management of delirium with agitation.

Due to the outbreak of COVID-19, we could not complete the trial to reach the calculated sample size, but our results are still promising. Further studies are supposed to evaluate the side effect profile of Neurogol and longer duration of treatment with more patients.

Finally, it should be noted that the addition of Neurogol to quetiapine can improve agitation in patients with delirium and shorten ICU stay. Of course, more research is needed to investigate the role of herbal medicines in ICUs and their efficacy and safety.

\section{OrCID}

Babak Alikiaie (1) https://orcid.org/0000-0003-3236-1970 Erfan Shahmoradi (1) https://orcid.org/0000-0001-7190-9201 Afsaneh Yekdaneh (1) https://orcid.org/0000-0001-9094-8943 Sarah Mousavi @ https://orcid.org/0000-0001-9792-1428

\section{References}

1. Krewulak KD, Stelfox HT, Leigh JP, Ely EW, Fiest KM. Incidence and prevalence of delirium subtypes in an adult ICU: a systematic review and meta-analysis. Crit Care Med2018;46(12):2029-2035.DOI: 10.1097/ CCM.0000000000003402.

2. TangLL. ICUdelirium:aconceptanalysis. TMRIntegrNurs2018;2(1):18-26. DOI: 10.12032/TMRIN20180310.

3. Celis-Rodríguez E, Cortés JD, Bolívar YC, González JC, Pinilla DI, Záccaro LF, et al. Evidence-based clinical practice guidelines for the management of sedoanalgesia and delirium in critically ill adult 
patients. MedIntensiva (English Edition)2020;44(3):171-184.DOI: 10.1016/j.medin.2019.07.013.

4. Blair GJ, Mehmood T, Rudnick M, Kuschner WG, Barr J. Nonpharmacologic and medication minimization strategies for the prevention and treatment of ICU delirium: a narrative review.J Intensive Care Med 2019;34(3):183-190. DOI: 10.1177/0885066618771528.

5. Nikooie R, Neufeld KJ, Oh ES, Wilson LM, Zhang A, Robinson KA, et al. Antipsychotics for treating delirium in hospitalized adults: a systematic review. Ann Intern Med2019;171(7):485-495.DOI: 10.7326/ M19-1860.

6. Zaal IJ, Devlin JW, Hazelbag M, Klouwenberg PMK, van der Kooi AW, Ong DS, et al. Benzodiazepine-associated delirium in critically ill adults. Intensive Care Med 2015;41(12):2130-2137.DOI: 10.1007/s00134-0154063-z.

7. $\mathrm{Ng} \mathrm{K}$, Shubash C, Chong J. The effect of dexmedetomidine on delirium and agitation in patients in intensive care: systematic review and metaanalysis with trial sequential analysis. Anaesthesia2019;74(3):380-392. DOI: 10.1111/anae.14472.

8. Levy I, Attias S, Ben-Arye E, Bloch B, Schiff E. Complementary medicine for treatment of agitation and delirium in older persons: a systematic review and narrative synthesis. Int JGeriatr Psychiatry2017;32(5):492-508. DOI:10.1002/gps.4685.

9. Matsumoto-Miyazaki J, Ushikoshi H, Miyata S, Miyazaki N, Nawa T, Okada $\mathrm{H}$, et al. Acupuncture and traditional herbal medicine therapy prevent deliriumin patients with cardiovascular disease in intensive care units. Am J ChinMed 2017;45(02):255-268.DOI: 10.1142/ S0192415X17500161.

10. Bannon L, Mc Gaughey J, Verghis R, Clarke M, Mc Auley DF, Blackwood $B$. The effectiveness of non-pharmacological interventions in reducing the incidence and duration of delirium in critically ill patients: a systematic review and meta-analysis. Intensive Care Med 2019;45(1):1-12.DOI: 10.1007/s00134-018-5452-x.

11. Ke L, Wang J, Ma Z, Chen B, Wang L, Gong J, et al. Non-pharmacological treatment of intensive care unit delirium. Am J Nurs Sci 2019;8(3): 119-128.DOI: 10.11648/j.ajns.2019 0803.17.

12. Moradkhani H, Sargsyan E, Bibak H, Naseri B, Sadat-Hosseini M, Fayazi-Barjin A, et al. Melissa officinalis L., a valuable medicine plant: are view. J Med Plant Res 2010;4(25):2753-2759. DOI: 10.5897/JMPR.9000881.

13. López V, Martín S, Gómez-Serranillos MP, Carretero ME, Jäger AK, Calvo MI. Neuroprotective and neurological properties of Melissa officinalis. NeurochemRes2009;34(11):1955-1961.DOI: 10.1007/ s11064-009-9981-0.

14. Buchwald-Werner S, Vazquez I. Effects of a Melissa officinalis special extract on mood and cognitive function. Planta Med2015;81(16):SL5C_01. DOI: 10.15171/jhp.2019.19

15. Akhondzadeh S, Noroozian M, Mohammadi M, Ohadinia S, Jamshidi A, Khani M. Melissa officinalis extract in the treatment of patients with mild to moderate Alzheimer's disease: a double blind, randomised, placebo controlled trial. J Neurol Neurosurg Psychiatry2003;74(7):863-866.DOI:10.1136/jnnp.74.7.863.

16. Miraj S, Azizi N, Kiani S. A review of chemical components and pharmacological effects of Melissa officinalis L. Der Pharmacia Lettre2016;8(6):229-237.

17. Shakeri A, Sahebkar A, Javadi B. Melissa officinalis L.-areview of its traditional uses, phytochemistry and pharmacology.
J Ethnopharmacol2016;188:204-228.DOI: 10.1016/j. jep.2016.05.010.

18. Dastmalchi K, Ollilainen V, Lackman P, af Gennäs GB, Dorman HD, Järvinen PP, et al. Acetylcholinesterase inhibitory guided fractionation of Melissa officinalis L. Bioorg Med Chem 2009;17(2):867-871. DOI: 10.1016/j.bmc.2008.11.034.

19. Plushner SL. Valerian: Valeriana officinalis. Am J Health-system Pharm2000;57(4):328-335.DPO: 10.1093/ajhp/57.4.328.

20. Murti K, Kaushik M, Sangwan Y, Kaushik A. Pharmacological properties of Valeriana officinalis- a review. Pharmacology2011;3:641-646.

21. Sheikhani A, Kholdi N, Mokhtari M. An overview of the most effective tranquilizer herbs. J Basic Clin Pathophysiol 2017;5(2):27-34.DOI: 10.22070/JBCP.2017.2498.1078.

22. Gusmao-Flores D, Salluh JIF, Chalhub RÁ, Quarantini LC. The confusion assessment method for the intensive care unit (CAM-ICU) and intensive care delirium screening checklist (ICDSC) for the diagnosis of delirium: a systematic review and meta-analysis of clinical studies. CritCare2012;16(4):R115.DOI: 10.1186/cc11407.

23. Ely EW, Truman B, Shintani A, Thomason JW, Wheeler AP, Gordon S, et al. Monitoring sedation status over time in ICU patients: reliability and validity of the Richmond Agitation-Sedation Scale (RASS). JAMA2003;289(22):2983-2991.DOI: 10.1001/jama.289.22.2983.

24. Zolfaghari M, Arbabi M, Pedram Razi S, Biat K, Bavi A. Effectiveness of a multifactor educational intervention on delirium incidence and length of stay in patients with cardiac surgery. J Hayat 2012;18(1):67-78.

25. Heidari A, Dianati M, Mousavi G. Prevalence of delirium, its related factors and short-term outcomes in ICU wards of Kashan ShahidBeheshti and Isfahan Kashani hospitals during 2012-2013. Feyz J Kashan Univ Med Sci 2014;18(1).

26. Ghafari S, Esmaeili S, Aref H, Naghibi F, Mosaddegh M. Qualitative and quantitative analysis of some brands of valerian pharmaceutical products. Stud Ethno-Med2009;3(1):61-64.DOI:10.1080/09735070.2 009.11886339.

27. Watson K, Hatcher D, Good A. A randomised controlled trial of Lavender (Lavandula angustifolia) and Lemon Balm (Melissa officinalis) essential oils for the treatment of agitated behaviour in older people with and without dementia. Complementary Ther Med 2019;42:366-373.DOI: 10.1016/j.ctim.2018.12.016.

28. Elliott MS, Abuhamdah S, Huang L, Perry EK, Ballard C, Lees G, et al. P1-435: essential oils as potential treatment for agitation in severe dementia: Elucidation of the pharmacological mechanism of Melissa and Lavender oils. Alzheimers Dement2006;2:S225-S. https:// doi.org/10.1016/j.jalz.2006.05.814

29. Andreatini R, Sartori VA, Seabra ML, Leite JR. Effect of valepotriates (valerian extract) in generalized anxiety disorder: a randomized placebo-controlled pilot study. Phytother Res 2002;16(7):650-654. DOI: 10.1002/ptr.1027.

30. Trompetter I, Krick B, Weiss G. Herbal triplet in treatment of nervous agitation in children. Wien Med Wochenschr 2013;163(3-4):52-57. DOI:10.1007/s10354-012-0165-1.

31. Hosker C, Ward D. Hypoactive delirium. BMJ2017;357. DOI: 10.1136/ bmj.j2047.

32. O'Keeffe ST, Lavan JN. Clinical significance of delirium subtypes in older people. Age and ageing. 1999;28(2):115-119.DOI: 10.1093/ ageing/28.2.115. 